\title{
Testing of Beeswax Printing Technology in the Design of a Paper-Based Microfluidic System
}

\author{
Immanuel Nunut ${ }^{1}$, Yudan Whulanza ${ }^{1,3^{*}}$, Samuel Kassegne ${ }^{2}$ \\ ${ }^{1}$ Department of Mechanical Engineering, Faculty of Engineering, Universitas Indonesia, Kampus UI Depok, \\ Depok 16424, Indonesia \\ ${ }^{2}$ Department of Mechanical Engineering, College of Engineering San Diego State University, CA 92182, United \\ States \\ ${ }^{3}$ Research Center for Biomedical Engineering (RCBE), Universitas Indonesia, Kampus UI Depok, Depok 16424, \\ Indonesia
}

\begin{abstract}
The development of additive manufacturing technologies has the advantage of producing more economical and efficient products. This trend is supported by the fact that this technology is extensively developed, so that it has easy platforms to use, vast applications, and is more economically affordable than it was when it was first created in the early 90s. Currently, this technology is also widely applied in the bioengineering field to produce so called micro-scale products. In this study, a beeswax printer was developed by modifying a universal 3D printer to apply beeswax as a microchannel part on paper. Ultimately, this application shall be used for paper lab-on-a-chip (LOC) that enables us to perform specific functions, such as biological detection. However, a thorough study is needed to understand the limitations of this beeswax printer, along with the characterization of its product. Here, an experiment was conducted to find the optimum conditions of the system with two main parameters, namely the heating characteristics and flowability of the molten beeswax during the printing process. Additionally, an analytical model was also developed to validate the phenomena of this advanced printing media. Briefly, the beeswax printer allowed us to have a fine profile in the range of $0.5-2.0 \mathrm{~mm}$ wide and 30-150 $\mu \mathrm{m}$ thick. This research allowed us to find the desired profile of printed beeswax.
\end{abstract}

Keywords: Additive manufacturing; Beeswax; Microchannel; Paper LOC; 3D printer

\section{Introduction}

Lab-on-a-chip (LOC) is a device that integrates a series of laboratory processes on a chip to perform a specific task, such as pathogen detection, via serology or molecular identification (Oh, 2012; Jung et al., 2014; Luka et al., 2015). It can facilitate clinical measures, such as to filtrate/separate raw material, transport chemical reagents, perform a reaction, and detect biochemical results (Lim et al., 2010; Takenaga, 2015). It has small dimension so that this device can be easily transported. Because of its small size, it requires smaller specimens and reagents for its operation, i.e. microfluidic system (Ho et al., 2015; Lafleur et al., 2015). Thus, it has a much cheaper operational cost compared to conventional systems.

Microfluidic system are fabricated by etching or molding glass, silicone, acrylics, or 
other polymer types (Romao et al., 2017; Economou et al., 2018). In general, the polymer material is easily produced and performs well (Whulanza et al., 2017a, 2018a, 2019; Phadke et al., 2018; Renatan et al., 2020). However, paper-based lab-on-a-chip (LOC) is the latest innovation, with the advantage of a low fabrication cost (Martinez et al., 2010; Ballerini et al., 2012; Costa et al., 2014). This can be done by using hydrophilic and hydrophobic parts to control liquid regimes at an efficient cost (Zhang et al., 2013; Xue et al., 2017). This tuning of a paper surface can be easily realized by using a wax material as designed by Lee et al. (2019) and Kim and Noh (2018).

Fluidic channels can be patterned using wax screen printing (Dungchai et al., 2011) and dipping the object directly on the specimen (Songjaroen et al., 2011). Screen printing and spray methods have also been used to create a wax channel (Juang et al., 2017; Liu et al., 2017). A recent study also showed the role of additive manufacturing in wax coatings (Yamada et al., 2015).

An additive manufacturing platform, or 3D printer, has been widely used in deploying material through nozzles with various driving forces, such as pneumatic, piston, and motor movement (Naghieh et al., 2017). Thus, it enables us to deposit any material required, such as polymer filaments, hydrogel, ceramic, or composites of these substances (Whulanza et al., 2017b; Syuhada et al., 2018; Roopavath et al., 2019). Moreover, wax has also been used as a material in printing (Lu et al., 2009; Carrilho et al., 2009). However, further testing and characterization has yet to be applied to LOC fabrication (Xue et al., 2017).

This report explains the characterization of printed beeswax on a filter paper to be used as a microchannel. The measurements showed that optimum parameters achieved by our home-made wax printer inspired by batik printing art. Furthermore, an analytical model was demonstrated to approach the experimental results of printed wax. Ultimately, the wax channel was shown to be functionally resistant to liquid water adsorption.

\section{Methods}

\subsection{Beeswax Material}

The beeswax used in this experiment was purchased from an Indonesian local manufacturer Biopolish (Yogyakarta, Indonesia). The properties were as follows: melting temperature was $62.3^{\circ} \mathrm{C}$, latent heat was $141.5 \mathrm{~kJ} / \mathrm{kg}$ (when melting) and $145.6 \mathrm{~kJ} / \mathrm{kg}$ (when solidified), and the density was $789.5 \mathrm{kgm}^{-3}$ (when melting) and $819.8 \mathrm{kgm}^{-3}$ (when solidified) (Putra et al., 2016; Amin et al., 2017).

Table 1 Properties of beeswax material

\begin{tabular}{ll}
\hline \multicolumn{1}{c}{ Properties } & \multicolumn{1}{c}{ Beeswax } \\
\hline Melting Temperature $\left({ }^{\circ} \mathrm{C}\right)$ & 62.28 \\
\hline Latent Heat $(\mathrm{kJ} / \mathrm{kg}]$ & 141.5 (molten state) \\
\hline \multirow{2}{*}{ Density $\left(\mathrm{kgm}^{-3}\right)$} & 145.6 (solid state) \\
\hline Heat Capacity $(\mathrm{kJ} / \mathrm{kg} \mathrm{K})$ & 819.5 (molten state) \\
\hline
\end{tabular}

\subsection{Beeswax Printer Setup}

In this study, a 3D Folger Tech RepRap Printer Prusa I3 was modified by eliminating the $x-y-z$ motor directions into a single axis motor direction and 2 other directions were fixed. The filament nozzle was then replaced with an electronic batik canting, which acted as an extruder head with a $0.8 \mathrm{~mm}$ diameter. Generally, canting is a traditional ink-pen used 
to apply wax on fabrics with specific batik motifs. Figure 1 shows the setup of the modified 3D printer with a filter paper underneath for printing.

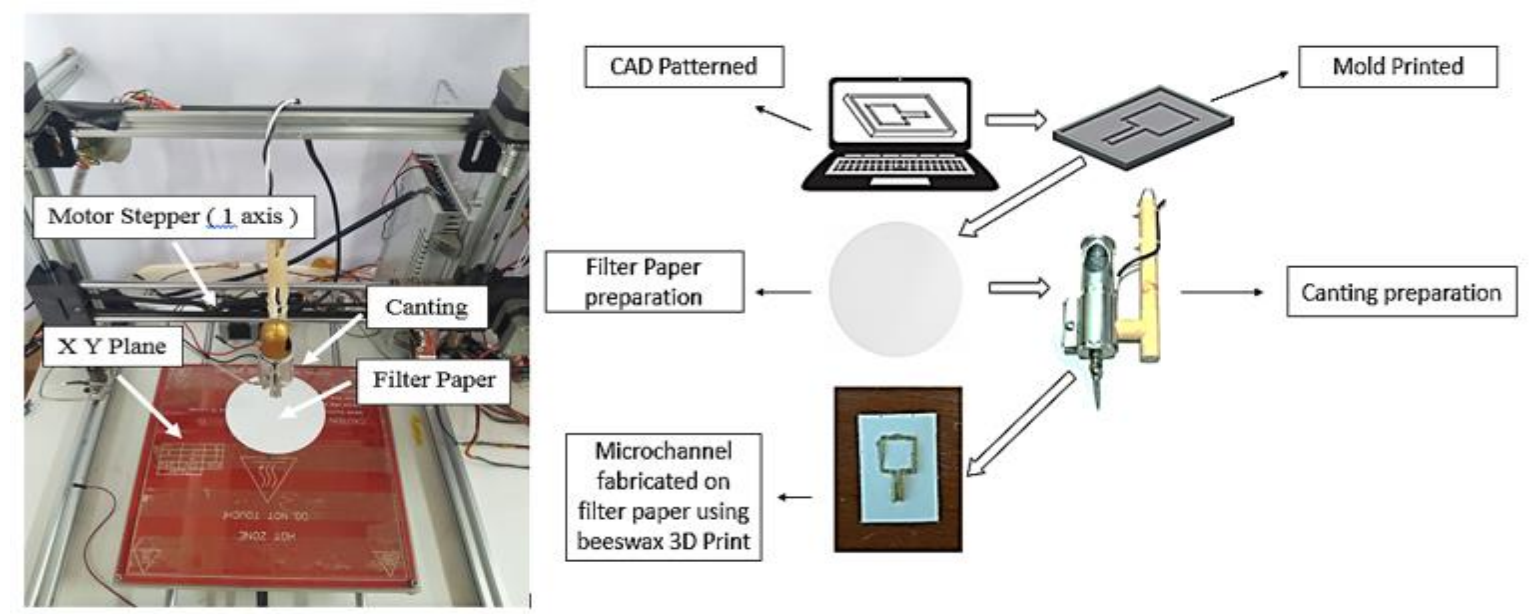

Figure 1 Experiment set-up and apparatus for beeswax printing

The layout of microchannels were previously drafted using any computer-aided-design (CAD) software and uploaded on the wax printer mainframe. The software enabled us to arrange the speed movement of the $\mathrm{x}$-axis, the so-called layer rate, and stabilize the temperature of canting. Once the set temperature of the bed and canting were reached, the motor stepper was activated to move the canting and extrude liquid beeswax along the predetermined profile. Later, the liquid beeswax was patterned on filter paper and solidified instantly to configure the microchannel.

\subsection{Beeswax Profile Characterization}

The beeswax printer was observed to understand the dependency between operating parameters, such as heating temperature of beeswax and speed movement of canting with the geometric wax profile. The heating temperature of canting was set at 60,70 , or $80^{\circ} \mathrm{C}$, whereas the speed of movement, or the so-called layer rate of the canting, were set at 11.5 , $22.5,45.0$, and $90 \mathrm{~mm} / \mathrm{s}$. The profile of beeswax was observed using the profilometer Surfcom 2900SD3. Each measurement was repeated for 5 specimens. Moreover, the observation of hydrophobicity testing was conducted using a digital microscope Dino-Lite AM4113 by dropping 20 microliters of deionized water on the channel.

\subsection{Analytical Model of Beeswax}

The geometric beeswax profile was estimated using an analytical model that has been used in previous work with gelatin printing (Whulanza et al., 2018b). The liquid wax, to some extent, was predicted to have a similar behavior to that of a Newtonian liquid. Therefore, a combination of continuity flow and Poiseuelle's approach were used (Whulanza et al., 2018b). The experimental area of the beeswax profile was obtained by multiplying the measured width and height profile.

$$
\begin{gathered}
Q=\frac{d V}{d t}=a h \frac{d l}{d t}=a h v_{x y} \\
Q=\frac{\pi r^{4}}{8 \mu} \frac{d p}{d z} \\
a h=\frac{\pi r^{4}}{8 \mu h v_{x y}} \frac{d p}{d z}
\end{gathered}
$$




$$
\mathrm{ah}=\sqrt{\frac{\pi \mathrm{r}^{4}}{8 \mu v_{\mathrm{xy}}} \frac{\mathrm{P}}{\mathrm{h}_{\mathrm{z}}}}
$$

where:

$\mathrm{Q}$ : volume of printed wax $\left(\mathrm{m}^{3}\right)$

$\mathrm{r}$ : diameter of the canting's nozzle (m)

$\mu \quad$ : average viscosity of beeswax during extrusion process (Pas)

$\mathrm{h}$ : effective elevation of extrusion process (m)

a : width of beeswax profile $(\mathrm{m})$

$\mathrm{h}_{\mathrm{z}}$ : distance of nozzle tip and base $(\mathrm{m})$

$\mathrm{v}_{\mathrm{xy}}$ : layer rate or velocity of nozzle in $\mathrm{x}$ or $\mathrm{y}$ direction relative to the base $(\mathrm{m} / \mathrm{s})$

$\mathrm{P}$ : applied pressure the volume of beeswax $(\mathrm{Pa})$

\section{Results and Discussion}

\subsection{Geometric Characterization of Beeswax Printing}

Beeswax printing had the ability to deposit beeswax onto the surface of filter paper. The movement of the canting's nozzle was arranged in an $x-y$ direction to produce a fine line of beeswax following the predetermined pattern. Figure 2 depicts the printing result and the test with a small drop of water (circa 20 microliter). The resulting print was able to trap the water inside of the line (Figure $2 \mathrm{~b}$ ). However, water spilled outside of the printed line at certain operational parameters (Figure 2c). Figure $2 \mathrm{~d}$ shows the cross-section area of filter paper to view a different color, indicating adsorbed beeswax. It was conjectured that this layer is a permeable layer for resisting liquid water (Destyorini et al., 2016; Plazonic et al., 2020).
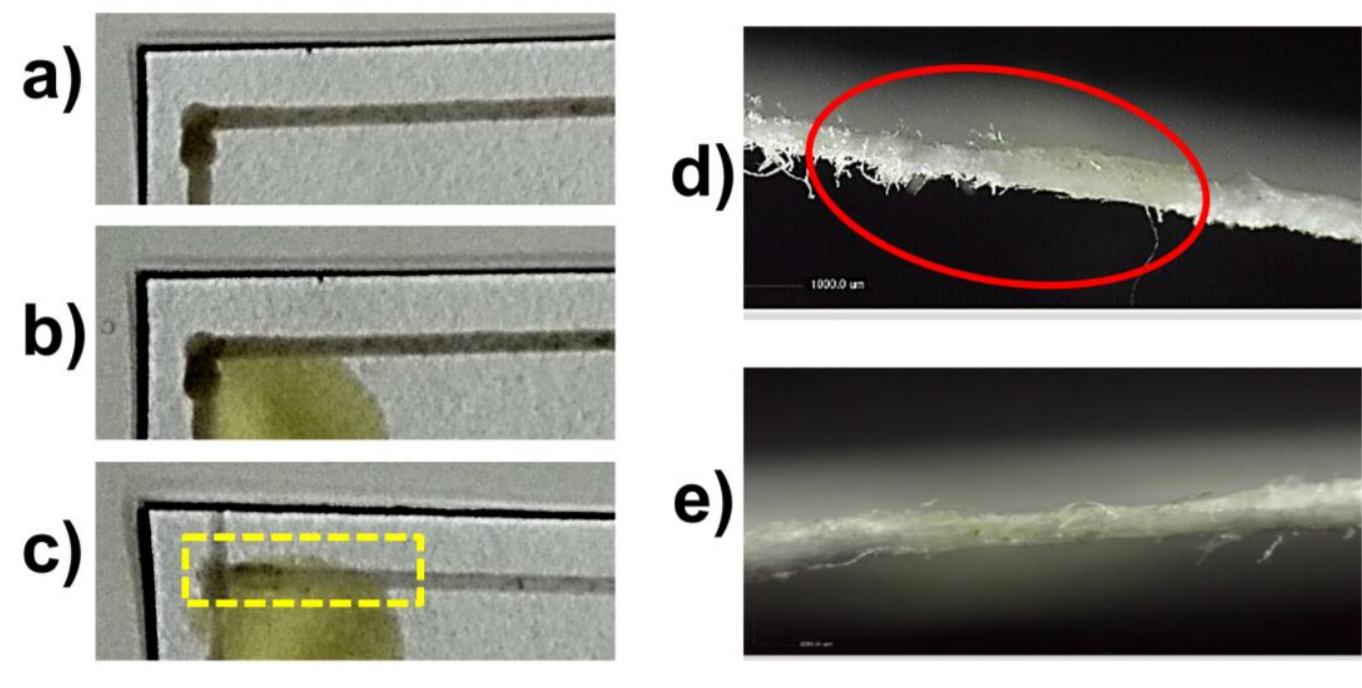

Figure 2 Observation of beeswax profile on the filter paper: (a) before; and (b-c) after a small volume of water was added

Figure 3 shows the printed beeswax on paper at various layer rates at the same canting's nozzle temperature, i.e. at $70^{\circ} \mathrm{C}$. Figuratively, the viscosity of molten beeswax is dependent on temperature and shear force, which was represented by the nozzle movement, i.e. layer rate. The current study shows that the higher the shear force of molten beeswax, the lower viscosity it has. Therefore, it is important to understand our optimum parameter process (beeswax heating temperature and layer rate). Figure 3 depicts the 
width of the beeswax profile, which tended to be smaller but thickened as the movement rate increased.
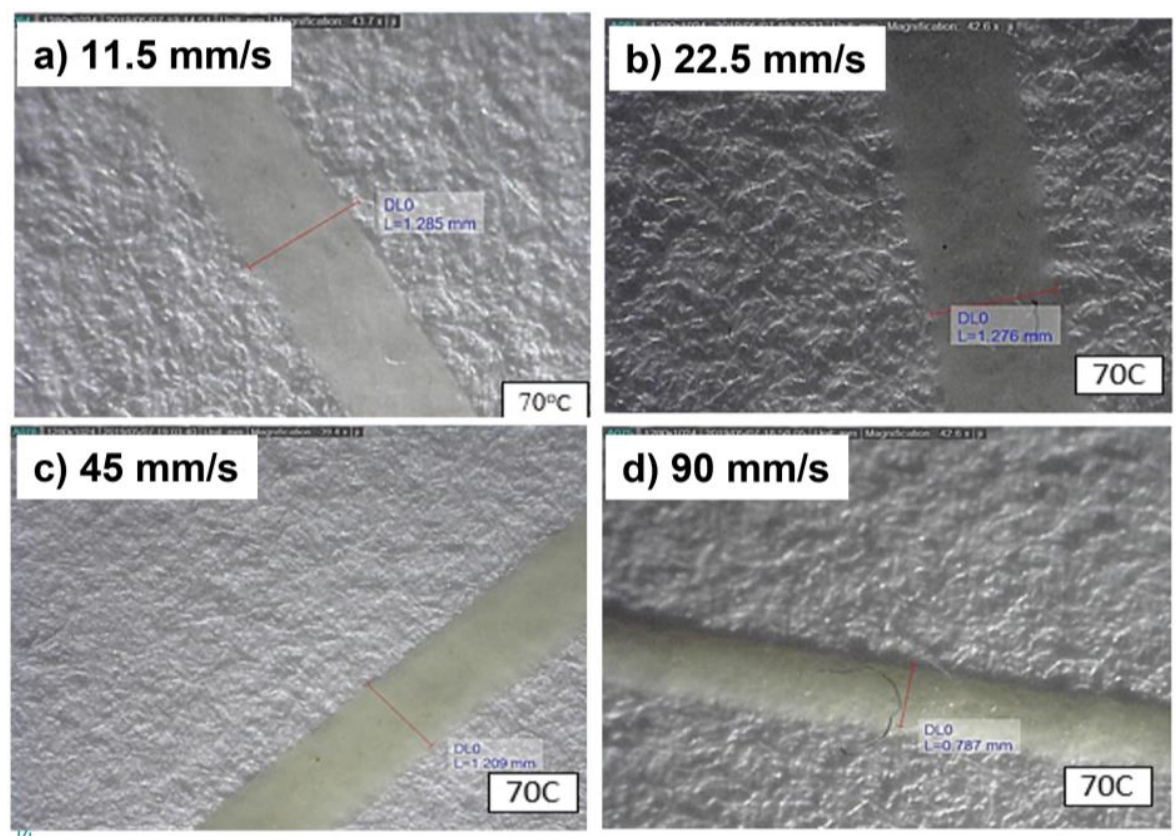

Figure 3 Observation of beeswax profile at various layer rates with the temperature of canting set at $70^{\circ} \mathrm{C}$

Figure 4 shows the results of the profilometer measurement for printed beeswax at various layer rates at a heating temperature of $70^{\circ} \mathrm{C}$. The stylus of the profilometer was contacted through the printed line and gave the reading profile as observed in Figure 4 . This profile gave information on the width and thickness of the printed line in advance.
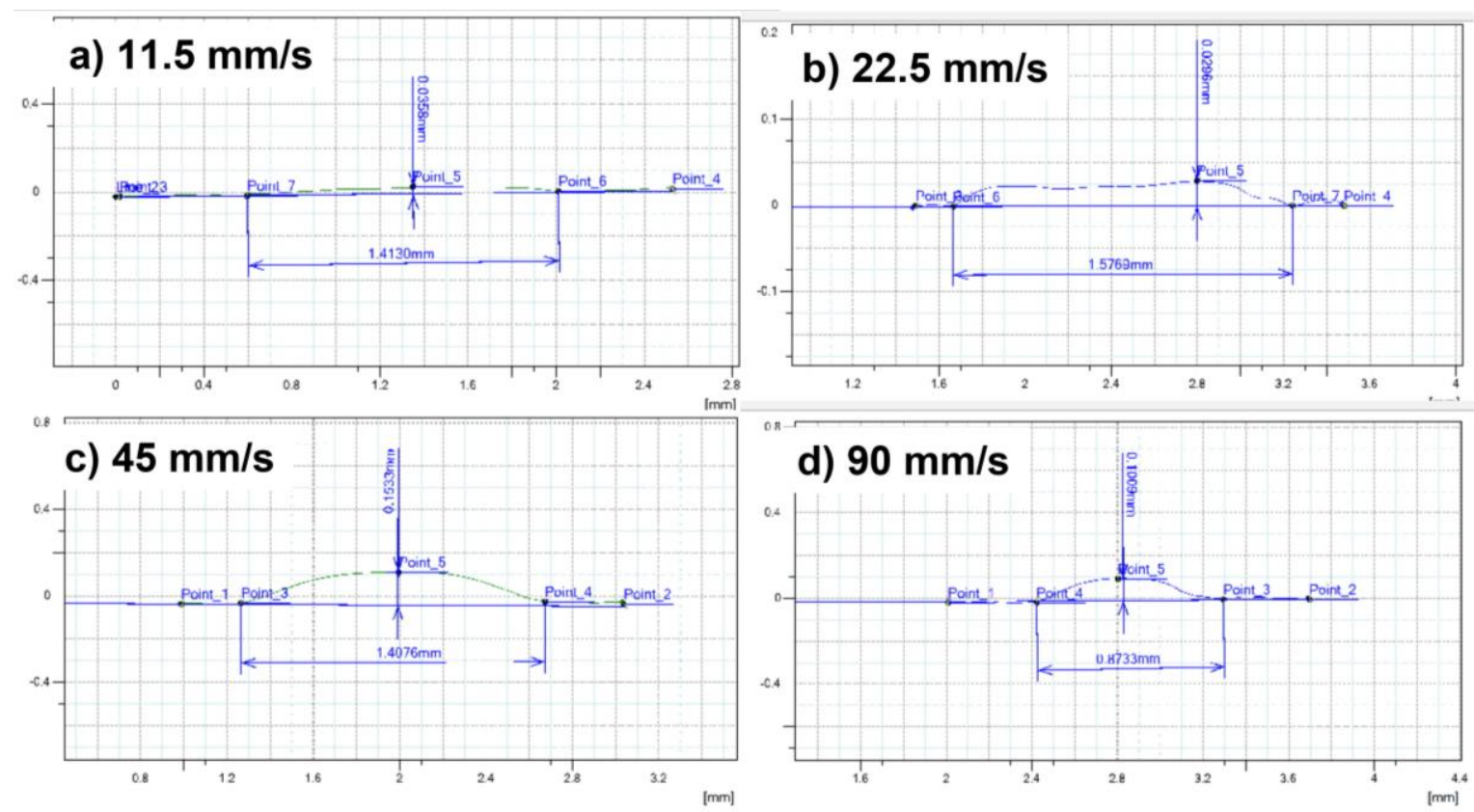

Figure 4 Measurements of the beeswax profile using a profilometer at various layer rates with the temperature of canting set at $70^{\circ} \mathrm{C}$ 
The profilometer results confirmed that the higher layer rate produced a shape in the printed wax with a lower width and thicker profile (Figure $5 \mathrm{a}$ ). Our study showed that the optimum height among all various rates was obtained at $45 \mathrm{~mm} / \mathrm{s}$ (Figure 5b). A crosssection area was calculated based on the two measured parameters (width and thickness), as depicted in Figure 5c. Here, the measured height indicated the maximum height of the profile and was used in cross-section area calculation. Figure $5 \mathrm{c}$ also showed that the profile of the cross-section area was not a perfectly rectangular area. However, we used this assumption to simplify our approach to find the analytical model of the cross-section area. Based on our aims, it was more important to understand the trend of the resulting area rather than the accuracy of the analytical model. Figure $5 \mathrm{~d}$ shows that the cross-section area followed the trend of height rather than the width of the printed beeswax.

a)

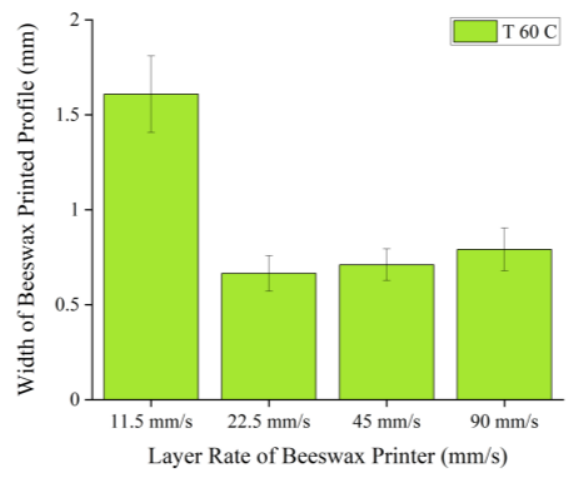

c)

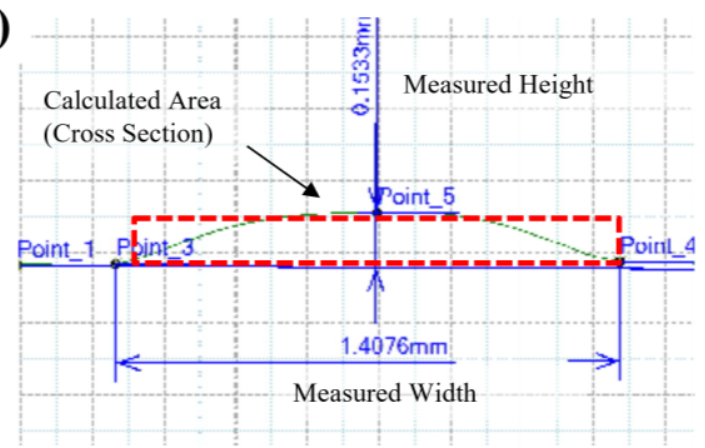

b)

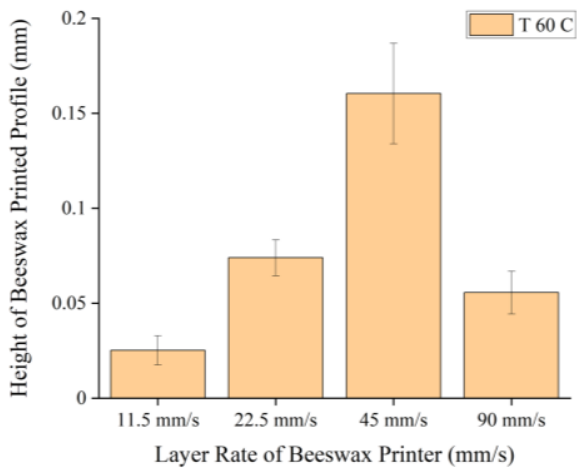

d)

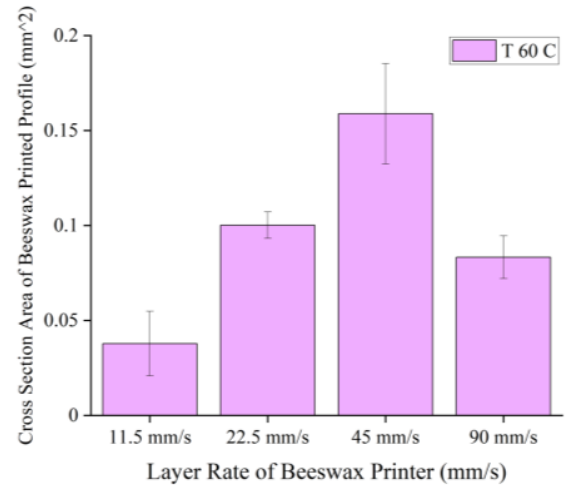

Figure 5 Measurements of beeswax profile using a profilometer at various layers with the temperature of canting set at $70^{\circ} \mathrm{C}$

Supplementary Figure 1 summarizes the trend of the cross-section area of printed profiles with respect to the operating parameters, i.e. heating of beeswax and movement rate in the canting's nozzle. It was confirmed that the highest area was achieved at a moderate layer rate of $45 \mathrm{~mm} / \mathrm{s}$, whenever beeswax was heated at 60 and $70^{\circ} \mathrm{C}$. At a layer rate of $90 \mathrm{~mm} / \mathrm{s}$. the cross-section area decreased with both the width and height profile. It was predicted that solidification occurred faster during the printing process. In contrast, when heating beeswax at $80^{\circ} \mathrm{C}$, the cross-section area still increased with the increase in the layer rate. It can be conjectured that the amount of molten metal was still extruded from the nozzle at the layer rate of $90 \mathrm{~mm} / \mathrm{s}$. Thus, the cross-section area that represented the mass flow of beeswax was increasing. This is a condition where the phase of beeswax was at a liquid phase during printing, thus, the mass flow plays a dominant role in forming the wax profile (Suprapto et al., 2020). 


\subsection{Analytical Model of Beeswax Printing}

An analytical model was introduced to approach the printing phenomena of liquid beeswax. It was assumed that the beeswax extruded out of the nozzle in its liquid phase, solidified instantly on the surface. Supplementary Figure 2a describes the molten wax flow by its weight with a constant viscosity, according to its temperature. The nozzle was then moved in the $v$ direction and formed a printed line with a width of one $\mathrm{mm}$. Equation 4 gives a prediction of width of the printed beeswax on the surface.

The experimental data of the printed line width are presented in Supplementary Figures $2 b$ and $2 c$ with various heating temperature of beeswax. They showed a similar trend for all heating temperatures, so that the line width decreased as the layer rate increased. Moreover, equation 4 was plotted on the charts to highlight the dependency of profile dimension on layer rate and heating temperature. Both analytical data and experimental data provided similar findings. It can be inferred that the operating temperature assured that the wax printing went accordingly.

The analytical data of printed beeswax has a margin error of 18,11 , and $17 \%$ for heating wax at 60,70 , and $80^{\circ} \mathrm{C}$, respectively. These results are comparable to the Schneider's group that worked with wax extrusion (around 10\%) (Takenaga et al., 2015). The difference was was that they used a numerical 3D computational flow diagram (www.flow3d.com) in their study.

\section{Conclusions}

The beeswax printer was successfully tested and thoroughly observed. The main task of this home-made device was to create microchannels as the main part of paper lab-on-achip. The microchannel was formed by printed beeswax that needs to allow the flow of a liquid specimen without further spillage outside of the required line. Therefore, it is important to understand the operating parameters of the beeswax printer to deliver quality. Here, it can be reported that heating temperature of beeswax materials in the device was $60-80^{\circ} \mathrm{C}$ and a layer rate of $11-90 \mathrm{~mm} / \mathrm{s}$. The device was able to produce printed wax $0.5-$ $2.0 \mathrm{~mm}$ wide and 30-150 $\mu \mathrm{m}$ thick. An analytical model was also introduced to validate the experimental results and shall be beneficial for further research.

\section{Acknowledgements}

This research was supported by the Kemristek BRIN PUPT 2020 with Contract Number: NKB-2872/UN2.RST/HKP.05.00/2020.

\section{References}

Amin, M., Putra, N., Kosasih, E.A., Prawiro, E., Luanto, R.A., Mahlia, T.M.I., 2017. Thermal Properties of Beeswax/Graphene Phase Change Material as Energy Storage for Building Applications. Applied Thermal Engineering, Volume 112(5), pp. 273-280

Ballerini, D.R., Li, X., Shen, W., 2012. Patterned Paper and Alternative Materials as Substrate for Low-cost Microfluidics Diagnostics. Microfluidics and Nanofluidics, Volume 13(5), pp. 769-787

Carrilho, E., Martinez, A.W., Whitesides, G.M., 2009. Understanding Wax Printing: A Simple Micropatterning Process for Paper-based Microfluidics. Analytical Chemistry, Volume 81(16), pp. 7091-7095

Costa, M.N., Veigas, B., Jacob, J.M., Santos, D.S., Gomes, J., Baptista, P.V., Martins, R., Inácio, J., Fortunato, E., 2014. A Low Cost, Safe, Disposable, Rapid, and Self-sustainable Paper- 
based Platform, for Diagnostic Testing: Lab-on-Paper. Nanotechnology, Volume 25(9), pp. 1-12

Destyorini, F., Subhan, A., Indayaningsih, N., Prihandoko, B., Zulfia, A., 2016. Preparation and Characterization of Carbon Composite Paper from Coconut Coir for Gas Diffusion Layer. International Journal of Technology, Volume 7(8), pp. 1283-1290

Dungchai, W., Chailapakul, O., Henry, C.S., 2011. A Low-Cost, Simple, and Rapid Fabrication Method for Paper-based Microfluidics using Wax Screen-Printing. Analyst, Volume 136, pp. 77-82

Economou, A., Kokkinos, C., Prodromidis, M., 2018. Flexible Plastic, Paper and Textile Labon-a Chip Platforms for Electrochemical Biosensing. Lab on a Chip, Volume 18(13), pp. 1812-1830

Ho, C.M.B., Ng, S.H., Li, K.H.H., Yoon, Y.J., 2015. 3D Printed Microfluidics for Biological Applications. Lab on a Chip, Volume 15(18), pp. 3627-3637

Juang, Y.-J., Li, W.-S., Chen, P.-S., 2017. Fabrication of Microfluidic Paper-based Analytical Devices by Filtration-assisted Screen Printing. Journal of the Taiwan Institute of Chemical Engineers, Volume 80, pp. 71-75

Jung, W., Han, J., Choi, J.W., Ahn, C.H., 2014. Point-of-Care Testing (POCT) Diagnostic System using Microfluidic Lab-on-a-chip Technologies. Microelectronic Engineering, Volume 132, pp. 46-57

Kim, M., Noh, J., 2018. Fabrication of a Hydrophilic Line on a Hydrophobic Surface by Laser Ablation Processing. Micromachines, Volume 9, pp. 208-218

Lafleur, J.P., Jönsson, A., Senkbeil, S., Kutter, J.P., 2015. Recent Advances in Lab-on-Chip for Biosensing Applications. Biosensors and Bioelectronics, Volume 76, pp. 213-233

Lee, K.K., Kim, M.O., Choi, S., 2019. A Whole Blood Sample-to-Answer Polymer Lab-on-aChip with Superhydrophilic Surface Toward Point-of-Care Technology. Journal of Pharmaceutical and Biomedical Analysis, Volume 162, pp. 28-33

Lim, Y.C., Kouzani, A.Z., Duan, W., 2010. Lab-on-a-Chip: A Component View. Microsystem Technologies, Volume 16, pp. 1995-2015

Liu, N., Xu, J., An, H.J., Phan, D.T., Hashimoto, M., Lew, W.S., 2017. Direct Spraying Method for Fabrication of Paper-based Microfluidic Devices. Journal of Micromechanics and Microengineering, Volume 27, pp. 1-10

Lu, Y., Shi, W., Jiang, L., Qin, J., Lin, B., 2009. Rapid Prototyping of Paper-based Microfluidics with Wax for Low-Cost, Portable Bioassay. Electrophoresis, Volume 30, pp. 1497-1500

Luka, G., Ahmadi, A., Najjaran, H., Alocilja, E., DeRosa, M., Wolthers, K., Malki, A., Aziz, H., Althani, A., Hoorfar, M., 2015. Microfluidics Integrated Biosensors: A Leading Technology towards Lab-on-a-Chip and Sensing Applications. Sensors, Volume 15(12), pp. 30011-30031

Martinez, A.W., Phillips, S.T., Whitesides, G.M., 2010. Diagnostic for Developing World: Microfluidic Paper-based Analytical Devices. Analytical Chemistry, Volume 82(1), pp. 3-10

Naghieh, S., Foroozmehr, E., Badrossamay, M., Kharaziha, M., 2017. Combinational Processing of 3D Printing and Electrospinning of Hierarchical Poly (Lactic Acid)/Gelatin-Forsterite Scaffolds as a Biocomposite: Mechanical and Biological Assessment. Materials and Design, Volume 133, pp. 128-135

Oh, K.W., 2012. Lab-on-Chip (LOC) Devices and Microfluidics for Biomedical Applications. In: MEMS for Biomedical Applications, Bhansali, S., Vasudev, A., (eds.), Woodhead Publishing Limited, Cambridge, UK, pp. 150-171 
Phadke, M., Shaner, S., Shah, S., Rodriguez, Y., Wibowo, D., Whulanza, Y., Teriete, P., Allen, J., Kassegne, S., 2018. Inertial Focusing and Passive Micro-Mixing Techniques for Rare Cells Capturing Microfluidic Platform. In: AIP Conference Proceedings, Volume 1933

Plazonic, I., Džimbeg-Malcic, V., Bates, I., Barbaric-Mikocevic, Ž., 2020. Effects of Photooxidation on the Properties of Hemp Office Papers. International Journal of Technology, Volume 11(2), pp. 215-224

Putra, N, Prawiro, E., Amin, M., 2016. Thermal Properties of Beeswax/CuO Nano Phasechange Material Used for Thermal Energy Storage. International Journal of Technology, Volume 7(2), pp. 244-253

Renatan, J., Irwansyah, R., Warjito, Whulanza, Y., 2020. Testing of Pneumatic Actuation Micro Valve Module for Lab-on-a-Chip Application. 2020, In: AIP Conference Proceedings, Volume 2227

Romao, V.C., Martins, S.A., Germano, J., Cardoso, F.A., Cardoso, S., Freitas, P.P., 2017. Lab-onChip Devices: Gaining Ground Losing Size. ACS Nano, Volume 11(11), pp. 10659-10664

Roopavath, U.K., Malferrari, S., Van Haver, A., Verstreken, F., Rath, S.N., Kalaskar, D.M., 2019. Optimization of Extrusion Based Ceramic 3D Printing Process for Complex Bony Designs. Materials and Design, Volume 162, pp. 263-270

Songjaroen, T., Dungchai, W., Chailapakul, O., Laiwattanapaisal, W., 2011. Novel, Simple, and Low-cost Alternative Method for Fabrication of Paper-based Microfluidics by Wax Dipping. Talanta, Volume 85(5), pp. 2587-2593

Suprapto., Gotoh, T., Humaidah, N., Febryanita, R., Firdaus, M.S., Ningrum, E.O., 2020. The Effect of Synthesis Condition of the Ability of Swelling, Adsorption, and Desorption of Zwitterionic Sulfobetaine-based Gel. International Journal of Technology, Volume 11(2), pp. 299-309

Syuhada, G., Ramahdita, G., Rahyussalim, A.J., Whulanza, Y., 2018. Multi-Material Poly (Lactic Acid) Scaffold Fabricated via Fused Deposition Modeling and Direct Hydroxyapatite Injection as Spacers in Laminoplasty. In: AIP Conference Proceedings, Volume 1933, p. 020008

Takenaga, S., Schneider, B., Erbay, E., Biselli, M., Schnitzler, Th., Schoning, M.J., Wagner, T., 2015. Fabrication of Biocompatible Lab-On-Chip Devices for Biomedical Application by Means of a 3D-Printing Process. Applications and Materials Science, Volume 212(6), pp. 1347-1352

Whulanza, Y., Aditya, R., Arvialido, R., Utomo, M.S., Bachtiar, B.M., 2017a. Ease Fabrication of PCR Modular Chip for Portable DNA Detection Kit. In; AIP Conference Proceedings, Volume 1817(1), p. 040006

Whulanza, Y., Arsyan, R., Saragih, A.S., 2018b. Characterization of Hydrogel Printer for Direct Cell-laden Scaffolds. In: AIP Conference Proceedings, Volume 1933, p. 040002

Whulanza, Y., Hakim, A.T., Utomo, S.M., Irwansyah, R., Charmet, J., 2019. Design and Characterization of Finger-Controlled Micropump for Lab-on-a-Chip Devices. Evergreen Journal, Volume 6(2), pp. 108-113

Whulanza, Y., Hidayaturarahmi, P., Kurniawati, T., Rahyussalim, A.J., 2017b. Realization and Testing of Multi-material 3D Printer for Bone Scaffold Fabrication. In: AIP Conference Proceedings, Volume 1817, p. 040001

Whulanza, Y., Utomo, M.S., Hilman, A., 2018a. Realization of a Passive Micromixer using Herringbone Structure. In: AIP Conference Proceeding, Volume 1933, p. 040003

Xue. Y.-Y., Zhang, W.-T., Zhang, M.-Y., Liu, L.-Z., Zhu, W.-X., Yan, L.-Z., Wang, J., Wang, Y.-R., Wang, J.-L., Zhang, D.-H., 2017. Development of a Paper-based Microfluidic Analytical Device by a More Facile Hydrophobic Substrate Generation Strategy. Analytical Biochemistry, Volume 525, pp. 100-106 
Yamada, K., Hanares, T.G., Suzuki, K., Citterio, D., 2015. Paper-based Inkjet-Printed Microfluidic Analytical Devices. Angewandte Chemie, Volume 54(18), pp. 5294-5310

Zhang, W., Xiao, H., Qian, L., 2013. Enhanced Water Vapour Barrier and Grease Resistance of Paper Bilayer-Coated with Chitosan and Beeswax. Carbohydrate Polymers, Volume 101, pp. 401-406 